\title{
Kernos
}

Revue internationale et pluridisciplinaire de religion grecque antique

$4 \mid 1991$

Varia

\section{N. Loraux, Les expériences de Tirésias}

\section{Vinciane Pirenne-Delforge}

\section{OpenEdition \\ Journals}

\section{Édition électronique}

URL : http://journals.openedition.org/kernos/516

DOI : $10.4000 /$ kernos.516

ISSN : 2034-7871

\section{Éditeur}

Centre international d'étude de la religion grecque antique

\section{Édition imprimée}

Date de publication : 1 janvier 1991

Pagination : 346-347

ISSN : 0776-3824

\section{Référence électronique}

Vinciane Pirenne-Delforge, « N. Loraux, Les expériences de Tirésias », Kernos [En ligne], 4 | 1991, mis en ligne le 06 avril 2011, consulté le 24 septembre 2020. URL : http://journals.openedition.org/kernos/ 516 ; DOI : https://doi.org/10.4000/kernos.516 
volumes of the Swedish Institute in Athens, for advancing understanding at the level of front-line research.

\section{Peter WARREN (Bristol)}

Nicole LORAUX, Les expériences de Tirésias. Le féminin et l'homme grec, Paris, Gallimard, 1989,397 p. 1 vol. 14 x 22,5 cm. (Nrf Essais). ISBN : 2-07-071700-3. Prix : 155 FF.

L'objectif principal de Nicole Loraux dans cet ouvrage, constitué de treize articles écrits entre 1977 et 1985, est de déterminer le plus exactement possible la place du féminin - et non des femmes puisqu'il s'agit moins d'étudier une réalité institutionnelle que des modes de représentation - dans le monde des hommes et à l'intérieur d'eux-mêmes. Contre les évidences du discours des Grecs sur la différence des sexes, ou plutôt dans les profondeurs mêmes de ces énonciations, l'A. débusque, entre autres, les larmes toutes féminines d'Achille, la souffrance des héros et des guerriers, dont l'ampleur ne se peut comparer qu'à l'épreuve douloureuse des parturientes, les ambiguïtés de la masculine Athéna que l'on retrouve inversées chez Hélène. Quant aux «expériences de Tirésias», sous le signe desquelles l'ouvrage déroule sa trame, elles s'articulent autour du corps invisible d'Athéna (Nicole Loraux se refuse, à vrai dire, à définir "ce que vit Tirésias»), de même que sur la révélation du plaisir des femmes. Héraclès, pour sa part, se trouve entièrement défini dans la juxtaposition des termes qui en introduisent l'étude : «le surmâle et le féminin».

Après avoir ainsi exploré les recoins les plus divers du domaine "mythico-religieux", Nicole Loraux change de décor mais pas de propos. Des historiens sont appelés à la barre pour témoigner de la place du naturel féminin dans l'histoire; il apparaît rapidement que la femme ne fait irruption sur la scène de l'histoire - c'est-à-dire essentiellement celle de la guerre - que dans des contextes de désordre intérieur - aux côtés des esclaves souvent, ces autres exclus du système - ou de situations extrêmes et exceptionnelles : elles s'arment alors et la victoire qu'elles remportent leur confere un peu de cette andreia qui leur est étrangère. On remarquera cependant que les traditions les plus explicites de l'intervention des femmes dans des événements d'apparence historique sont tardives et ne peuvent en aucun cas être conçues en dehors du registre "mythico-religieux». Entre l'événement pur et le récit imaginaire, $N$. Loraux se refuse à choisir, mais pose en conclusion le constat que c'est dans la sphère mythique et poétique «que se déroulent le plus à l'aise les fantasmes sur la bonne féminité qui se laisse approprier».

Si l'on se place du point de vue de l'histoire de la religion grecque celui qui nous intéresse directement -, l'ouvrage pourra agacer, mais 
séduira tout autant par l'aisance de son auteur à dessiner une telle fresque de l'imaginaire des Grecs. On souscrira volontiers au propos d'ensemble qui consiste à poser la féminité en repoussoir des qualités proprement masculines, avec toutes les interactions que cela implique entre les deux domaines. Mais certaines analyses sont d'une grande complexité, et leur raffinement est tel parfois que l'ingéniosité semble avoir pris le pas sur la rigueur.

Vinciane PIRENNE-DELFORGE (Liège)

Pierre SOMVILLE, Études grecques, Liège, Pierre Mardaga Éd., 1990, 1 vol., 172 p., 8 pl.

Ce livre est, au dire de l'A. lui-même, un "voyage zigzaguant à travers la mosaïque colorée ou le damier noir-et-blanc d'une Grèce à l'éternelle jeunesse». Reprenant ici diverses contributions publiées précédemment dans des revues spécialisées, Pierre Somville offre un véritable poème sur une civilisation toujours porteuse de sens à travers les siècles, jusque dans la plus infime de ses manifestations. Que ce soit dans l'analyse du motif du plongeon, du dauphin, dans l'étude des jeux de mots significatifs, et à travers tant d'autres essais de comparaison littéraire et iconographique, le lecteur ne peut que succomber au charme de cette sensibilité intuitive, qui ne craint pas de maltraiter la chronologie parfois.

Vinciane PIRENNE-DELFORGE (Liège) 